\title{
The Social Sustainability of Infrastructure: Constructing for Justice
}

\author{
Jessica Kaminsky ${ }^{1}$ *
}

\begin{abstract}
Socially sustainable infrastructure eliminates unfreedoms that reduce human choice and agency. These unfreedoms include the lack of clean energy, clean water, clean air, sanitation, mobility, information, or safe shelter, which collectively impact billions of people today, and the lack of a stable climate, which impacts everyone on earth and everyone who will be born in the coming decades. The built environment can be collaboratively built and collaboratively used to solve collective problems like these; in this sense, construction is a feminist project of creation. In this paper, I argue that the goal of all engineering projects and organizations must be a built environment that provides every person on the planet a greater ability to lead a life they value, recognizing that the diversity of those chosen lives is both the enabler and the outcome of what we pursue.
\end{abstract}

\section{Keywords}

Social Sustainability, Infrastructure, Sustainable Development Goals, Levitt Young Scholar Award

Since I first became a graduate student, the Engineering Project Organisation Society (EPOS) community has been deeply supportive of my research. The invitation to give the 2020 keynote presentation that was the basis of the text published here, paired with the incredible honour of having been the inaugural recipient of the Levitt Young Scholar Award in 2019, are just the most recent examples of that support. The award is particularly meaningful for me because of the high esteem I hold for the work and legacy of Ray Levitt, which is showcased throughout this intellectual community. Accordingly, I thank each member of EPOS for the firm support of my work, for always pushing me to improve and excel, and for creating so many of the excellent and stimulating ideas and theories that my research is based on.

In this paper, I sketch out some big ideas that have influenced my thinking, and that I see as the foundations of the social sustainability of infrastructure, which is what I study, always with particular attention to equity and vulnerable populations. I'll begin with the ideas that brought me back to grad school. Amartya Sen and Martha Nussbaum's ideas on human development have underpinned modern development theory and practice for decades. Fundamentally, their capability approach is founded on two core normative claims: first, that the freedom to achieve well-being is of primary moral importance, and second, that freedom to achieve well-being is to be understood in terms of people's real opportunities to do and be what they have reason to value (Nussbaum, 2011; Sen, 1999).

Sen is an economist-philosopher, and he doesn't just mean infrastructure when he talks about development. But I'm a civil engineer and that is what I am interested in; the boring stuff that

\footnotetext{
${ }^{1 *}$ Department of Civil and Environmental Engineering, University of Washington, Seattle, WA 98195, United States, jkaminsk@uw.edu (Corresponding Author)
} 
nobody notices until it breaks (Star, 1999), sewers and clean water and the lights coming on when you flip the switch. And I believe that civil infrastructure is absolutely fundamental to achieving human freedom, or people actually being able to lead the lives they choose to value. Not dying of cholera from dirty water, for example, rather expands your life choices.

But here is the unacceptable status of global infrastructure in 2020, in the most up to date statistics - much more problematic than even our unacceptable scores on the annual ASCE US infrastructure report cards (ASCE, 2020). More than 2 billion people without basic sanitation (JMP, 2020). 785 million people without access to clean water (JMP, 2019). About 800 million folks without electricity (IEA, 2020), and more people forcibly displaced from their homes than ever before in the history of the earth (UNHCR, 2020). To say the least, there is plenty of construction yet to be done if we are to remove these unfreedoms (Sen, 1999) from our society.

Now, I'm switching gears to talk briefly about some research my student Leigh Hamlet has done. I'm not only talking about this paper to highlight the top notch work that Leigh is doing. I'm doing it because this paper is a great answer to the question, Why do we build infrastructure? Why do we care about the infrastructure gaps I just described?

We don't build infrastructure for fun, and we don't do it because we like toilets in and of themselves. (Well, I do, I love toilets, but I do recognise not everyone shares that passion!). As Sen's framing suggests, we build infrastructure for people to use, because it makes our lives better and more free. In the example of Leigh's analysis, we find that reducing water fetching time correlates with higher math, reading, and writing scores, especially for girls. Those of you who don't spend as much of your time thinking about water and sanitation as I do may be wondering how much of a problem this really is - but I'm afraid to tell you that children around the world, usually girls, do indeed have to collect and carry water when there is no infrastructure (Hamlet et al., 2021)!

As I just described, global infrastructure disparities mean construction is big global business, and I have benefited enormously from many thinkers in this academic community who study global engineering projects, like Ray Levitt and Amy Javernick-Will. For many years they have called attention to the importance of these social issues in construction engineering.

For example, once upon a time I took a class from Dr Amy Javernick-Will, who introduced me to Hofstede's model of cultural difference and its proven relevance to global engineering projects (Hofstede, 2001). And one of the first things I did as an assistant professor was begin to explore what else quantitative models of cultural difference had to tell us about the design and management of global infrastructure projects. For example, I found statistically significant relationships between Hofstede's model of cultural difference and the technologies we choose for our water, sanitation ,and electrical infrastructure, for project delivery methods, and the way we permit construction projects

There are many relationships in that body of work I could discuss, but instead I'd like to synthesise a larger message of that combined work. Specifically, that message is that the design and management of infrastructure projects is not culturally neutral, and that this effect is strong enough you can see it at a statistically significant level in large global datasets. And this is perfectly intuitive given the links between people and our infrastructure that I described before.

In this body of work I am not in the least saying that some places do construction right and some do it wrong. Instead, I claim that these infrastructure technologies and practices are doing different cultural work depending on the values of the people who are building stuff. For example, one of these papers shows that if you value individualism, you are more likely to have renewables in your grid (Kaminsky, 2016). If you read the news you'll see folks on all ends of the political spectrum pursuing off grid power for this reason - they don't want to depend on outside organisations to control their electricity, which is so fundamental to quality of life.

Another thing we've done in this space is to create a new quantitative model of social difference, using fully transparent and replicable data science methods to analyse hundreds of thousands of 
survey responses about human values from the World Values Survey (WVS, 2020). This model gives us a new and updatable model for dimensions of social difference, using nationally representative data, and it allows these dimensions to emerge inductively from the data. It also accounts for the distribution of responses within each country, and provides scores for many lower income nations that do not have Hofstede scores available. We will soon have the first ever US State level quantitative model of social difference available. I hope that these models will help us all do a better job with accounting for social difference for both practice and research.

My attention to normative and cultural differences has probably made many of you think about the foundational work of Dick Scott, and of course I have greatly benefited from his work (Scott, 2013, etc.), and that of the many sociologists in this community who study engineering project organisation.

In an example of the ways these ideas have influenced my research, collaborators Miriam Hacker, Julie Faure, and Kasey Faust and I sought to understand how forces of legitimacy influenced attempts to provide water, sanitation, and shelter to refugees and asylum seekers arriving in Europe in 2015 during a mass exodus from the Middle East. Needless to say, there are enormous technical challenges involved in suddenly providing infrastructure services to millions of unexpected new folks who show up and who, until they get on their feet again, cannot immediately pay a water bill. So we interviewed the utilities, regulators, architects, and contractors who were involved in that work in both Germany and Sweden, where the greatest impacts were.

Once again we saw that normative and culturalcognitive forces overwhelmed the legal \& codified regulatory forces that some like to pretend control all aspects of engineering projects. Most folks found it immoral to leave refugees on the streets, and so they didn't, even if it broke building codes to pieces.

Of course, this means that we now have certain sociodemographic groups living in substandard housing that is less safe than those around them, also morally unacceptable to most folks, and this urgently needs to be addressed! Equity issues in the built environment are sticky, because of how long the assets stay around. Nevertheless, the point I'd like to make here is of the strength of those normative and cultural-cognitive forces. They overwhelmed even legal forces in this case, which I'd suggest is a good reason for thinking they also strongly impact other construction and infrastructure projects.

Here's another example of the ways in which our normative and cultural-cognitive theories of human behaviour influence our infrastructure systems. Over the summer of 2020 Kasey Faust and I, along with our students Lauryn Spearing and Nathalie Thelemaque and other faculty collaborators Lynn Katz, Kerry Kinney, Mary Jo Kirisits, and Lina Sela, were able to study the ways that social distancing from the COVID-19 pandemic changed the technical and organisational performance of water infrastructure systems (Spearing et al., 2020). Again linking the social to the technical in a rebounding chain, we design and construct infrastructure systems to be used in certain ways, with often tacit assumptions about theories of human behaviour behind them. Social distancing changed the timing, scale, and placement of water demands on our infrastructure systems, meaning that that one of the assumed models of human behaviour our designs were based on was suddenly wrong, or at least significantly more wrong than it usually us (because of course as a good engineer I believe that all models are wrong, but some are useful).

We talked to some utilities who hardly noticed a change, beyond managing workforce safety in a pandemic. Others experienced enormous impacts for example, $30 \%$ reductions in water demand that meant some water treatment plants had to be turned off to balance supply and demand. To generalise, what we found is that the technical impacts of the behavioural changes that happened because of social distancing depends on many contextual factors, including past system design and the distribution of water customer type.

To further generalise and theorise this finding, I'll turn to the last thinker I'm using to structure this presentation. Donna Haraway is a feminist thinker from UC Santa Cruz. She is perhaps best known for the idea of situated knowledge (Haraway, 1988), 
which I have come to believe is particularly useful for architecture, engineering, and construction (AEC) research and thinking. Haraway (like many feminists) eschews the idea of universal truths; this tradition is also well developed in science and technology studies that have for decades noted that even the pure sciences are intimately shaped by the people who perform the science (Latour, 1988).

This is a particularly useful frame for AEC professionals because our projects are unapologetically and unavoidably singular. Each of them is custom built and unique, which of course has led many of us to qualitative methods to study them. For example, the impacts of social distancing on water infrastructure was different in each context! However, rejecting singular universal truths does not lead us to relativism and the inability to know anything. Instead it leads us to contextualised, nuanced knowledge(s) that give us a better view of reality. To say this differently, Haraway argues (and I agree) that attending to these complications means we are doing better science - otherwise we are left with unacknowledged limitations in our work. For example, the answer to 'How did social distancing impact water utilities?' depends on many factors. The answer must be situated and contextual, or it is wrong.

This theoretical framing is useful for CEM work in many ways. One which I'd like to highlight here is methodological, with details available in a recent paper I wrote for the Journal of Construction Engineering and Management (JCEM) (Kaminsky, 2021). Through a content analysis of 12 months' of articles in JCEM, I found that $61 \%$ of these papers used data from or about people. Virtually all of these authors felt it was important to describe the people this knowledge was drawn from, presumably in order to let the reader know why what those people thought mattered - qualifying experts, in methodological jargon.

However, there is a wide range of the characteristics JCEM authors felt were important to report. Almost none, for example, note that because of the demographics of our industry, knowledge tends to be drawn from white, cis-gender American men, let alone discussing the ways that this sampling bias limited research results. How can we possibly claim to generalise from this kind of sample? And yet we do, repeatedly, and I include my own past work in that We.

But we can do better. That methods paper shows the respondent descriptors that at least some JCEM authors felt were important to report according to the content analysis. For example, these included respondents' job type or role, years of experience, subject matter expertise, geography or nationality, organisation and sector details, project type, professional qualifications, sex, race and ethnicity, ability, and language. If these things matter for some projects, they likely matter for all projects. But we simply don't know - that research has barely begun. Accordingly, I'd suggest the conservative way forward is to report on these characteristics at least until that research is done. This improves our science, by eliminating an ignored limitation that impacts more than half of the research being done in our professional community!

Functionally, and given the current demographics of the US CEM profession, a diversity-blind perspective means that while our studies claim generalizability to people in general, or construction managers in general, we are usually talking about white, non-disabled, English speaking, cis-gendered, American males, which is not a representative category. And, we are often not even recording details of professional experience that would better define their expertise. As a community, we should shift away from pretending that insights from this population can be unthinkingly generalised to all people just because we are not asking questions about identity and expertise categories. Instead, we should ask researchers to more closely describe the population(s) they are working with. This will help us to better see places where diverse populations are being excluded, and will make it harder to ignore and perpetuate the systematic disadvantages experienced by many groups. And as argued here, this change will also improve CEM science by eliminating an otherwise unspoken research limitation.

I'd like to use the last paragraphs of this paper to return to the big, infrastructural barriers to individual freedoms that our society face, and to the role that engineers, construction professionals, and our built environment play in eliminating 
these barriers. I'll paraphrase the late public health thought leader Hans Rosling (Rosling et al., 2018) in saying that while issues like the global coverage of safe sanitation, clean energy, and safe shelter are not yet good enough, they are at least getting better - we are making progress towards eliminating these infrastructure service gaps.

Climate change is different; we have not yet turned the corner to get to a place where things are, at least, getting better (IPCC, 2018). The fight against the ongoing climate crisis will define the coming decades; it is not a battle we can afford to lose. A stable climate is an absolutely essential assumption in our existing and past design and construction practices; it is absolutely essential to things we all care about, like for example the continued existence of our species. Even climate mitigation work is not enough; I have come to believe we must all turn our attention to preventing climate change, not by becoming climate scientists, but by harnessing our existing expertise and the incredible, collective power of the built environment.

I'll again turn to Haraway for a way to frame the climate challenge we have before us. In Haraway's words, "alone, in our separate kinds of expertise and experience, we know both too much and too little, and so we succumb to despair or to hope, and neither is a sensible attitude" (Haraway, 1988). Here she is writing about all kinds of destruction, not just climactic. But like Haraway I find myself to be deeply impatient with these two, too common reactions to the enormity of climate change. Neither despair nor limp hope without action is an acceptable option; our children and grandchildren will live with the consequences of what we do.

So, and again in Haraway's words, let us by all means be sensible, and reject hand wringing for calculated, implacable action. But what do we mean by being sensible about climate change \& sustainable global development? Certainly, these problems are too big for any one person to solve. Luckily enough I am a feminist myself, and accordingly I would shrug and point out that none of the big problems in history have been solved by a single hero, despite the stories we all grew up with. So what we really need, then, is calculated, implacable, collective action.
Luckily enough, the built environment that fascinates everyone in the AEC community is both collaboratively built and used to solve collective problems. In this sense, construction itself is a feminist project of creation, despite the gender disparities we note in the industry as it currently is. And specifically, no, it is not sensible to think that any single one of us can solve climate change. However, it is also not sensible to cede our agency and discount our contributions.

Technology doubtlessly has a role to play in solving the climate crisis, and we can collectively help society create a built environment that collectively pursues these big projects. For example, we can choose energy efficient buildings and green energy (collective solutions) rather than hoping everyone else will altruistically decide to make do without air conditioning and cars (individual solutions). Collaborative, situated, technical projects will be a fundamental part of the solutions to both the climate crisis and the sustainable global development goals.

To close, I would propose that our goal - the goal of every construction worker - must be a built environment that helps enable every person on the planet to lead a life they value, one in which we care for not only our own children but for those of all humanity through things like clean water, safe shelter, and a stable climate, recognising that the diversity of those chosen lives is both the enabler and the outcome of what we pursue.

Thank you very much.

\section{References}

ASCE. (2020), 2020 American Infrastructure Report Card. Reston, VA: ASCE.

Hamlet, L.C., Chakrabarti, S. and Kaminsky, J. (2021), "Reduced water collection time improves learning achievement among primary school children in India", Water Research, Vol. 203, 117527. 10.1016/j. watres.2021.117527

Haraway, D. (1988), "Situated knowledges: the science question in feminism and the privilege of partial perspective", Feminist Studies, Vol. 14 No. 3, pp. 575-599. 10.2307/3178066

Hofstede, G. (2001), Culture's consequences: comparing values, behaviors, institutions, and organizations across nations. Thousand Oaks, Calif: Sage Publications. 
IEA. (2020), Access to electricity - SDG7: Data and Projections - Analysis. Paris: IEA.

IPCC. (2018), Global Warming of 1.5 Degrees $C$. Geneva: IPCC.

JMP. (2019), Progress on household drinking water, sanitation, and hygiene | 2000 - 2017. Geneva: UNICEF/WHO.

JMP. (2020), State of the World's Sanitation: An urgent call to transform sanitation for better health, environments, economies and societies. Geneva: UNICEF/WHO.

Kaminsky, J. (2021), "Who are we talking to? situating construction engineering and management knowledge", Journal of Construction Engineering and Management, American Society of Civil Engineers, Vol. 147, 06020003. https://doi.org/10.1061/(ASCE) CO.1943-7862.0001977

Kaminsky, J.A. (2016), “Cultured construction: global evidence of the impact of national values on renewable electricity infrastructure choice", Environmental Science \& Technology, Vol. 50 No. 4, pp. 2108-2116. 10.1021/acs.est.5b05756

Latour, B. (1988), Science in Action: How to Follow Scientists and Engineers Through Society. Cambridge, Mass: Harvard University Press.

Nussbaum, M.C. (2011), Creating capabilities the human development approach. Cambridge, Mass: Belknap Press of Harvard University Press.
Rosling, H., Rosling, O. and Rosling Rönnlund, A. (2018), Factfulness: Ten Reasons We're Wrong About The World - And Why Things Are Better Than You Think. New York: Flatiron Books.

Scott, W.R. (2013), Institutions and Organizations: Ideas, Interests, and Identities. SAGE Publications. Los Angeles: Inc.

Sen, A.K. (1999), Development as Freedom. New York: Anchor Books.

Spearing, L.A., Thelemaque, N., Kaminsky, J.A., Katz, L.E., Kinney, K.A., Kirisits, M.J., Sela, L. and Faust, K.M. (2020), "Implications of social distancing policies on drinking water infrastructure: an overview of the challenges to and responses of U.S. utilities during the COVID-19 pandemic", ACS ES\&T Water, American Chemical Society, Vol. 1, pp. 888-899. https://doi.org/10.1021/acsestwater. 0c00229

Star, S.L. (1999), "The ethnography of infrastructure", American Behavioral Scientist, Vol. 43 No. 3, pp. 377-391. 10.1177/00027649921955326

UNHCR. (2020), "Figures at a Glance UNHCR", available at: https://www.unhcr.org/figures-at-aglance.html [Accessed 29 Jan 2021].

WVS. (2020), "WVS Database", available at: http:// www.worldvaluessurvey.org/WVSContents.jsp [Accessed 28 Jan 2020]. 